\title{
Doctors should be paid more
}

\author{
Andrew Hague* \\ Professor of Advanced Medicine, President of Cell Sonic Limited, Manufacturers of medical equipment, United Kingdom
}

Received: 眥 August 20, 2018; Published: 制 August 27, 2018

*Corresponding author: Andrew Hague, Professor of Advanced Medicine, President of Cell Sonic Limited, Manufacturers of medical equipment, United Kingdom

\begin{abstract}
Only by increasing productivity can earnings be increased. This applies to doctors as much as all trades. Better techniques enable diseases to be cured that have hitherto been impossible by traditional methods. By these means, a doctor can heal more patients more easily. Thus, a doctor can earn more, and patients be charged less.
\end{abstract}

\section{Introduction}

In every country, a medical doctor is highly respected and usually paid double the average wage and often much more especially if they can be self-employed and charge the patients directly. Governments and insurance companies always control the medical providers. Doctors are seen as having the power of life and death over people and this is feared by politicians who seldom understand medicine. So long as students continue to apply to medical schools, the renumeration is settled by supply and demand. If there are enough doctors, the pay must be enough. If doctors left the profession and fewer students enrolled, the pay would be increased to attract more.

All this assumes that a doctor is able to restore health and postpone death. Longevity has increased, so doctors and the medical industry claim to be earning their keep. But is living longer a result of what a doctor can do when called upon to stop an illness? What about the improvements in sanitation that happened over a hundred years ago in the modernised countries and are being installed now in emerging countries. Soap does more to maintain health than aspirin. It has to be said that a headache is never the result of an aspirin deficiency [1]. Plumbers contribute more to health than doctors. Some can earn as much as doctors by working hard and taking on unpleasant jobs. To become a doctor requires more study and expense than ever faces an apprentice plumber and the skills are different.

\section{The makings of a doctor}

Think back to school days. Those who passed exams all had good memories. They may have lacked imagination but when it came to remembering names and dates, they had total recall and that is all an exam tested. Medical students are similarly tested on their memory [2]. Now ask whether a good memory is more important than an instinct for asking the right questions when it comes to puzzling out what the cause of an illness is. Having learned a lot of case histories, a doctor may remember that what he sees in the clinic is the same as reported in a text book and on that basis prescribes drugs which should help. That, unfortunately, is not good practice and usually supplied with the advice, "If you don't feel better in a few days, come back and we'll try something else." Whether the medicine works or not, the doctor gets paid. By contrast, if the new toilet did not flush, the plumber would not be paid until it worked properly.

\section{A doctor's priority}

The doctor will have provided the patient with a medicine that can be justified as correct by reference to existing practice. It will have been used before and tested. Whether the circumstances are the same, one can never be sure but at least the uncertainties are limited if the drug, and it usually is a drug, has been around long enough to be well tested. This is all about legalities. The doctor's first responsibility is to protect himself and his colleagues. It is not about doing the best for the patient.

A patient who has not been treated by a doctor, cannot sue that doctor. This is now the first rule of medicine.

The language of medicine is deliberately non-conventional. It will be argued that it eliminates misunderstandings and can be more precise. So, who misunderstands? It is always the patient. 
Who dares to argue with a doctor? His rebuttal will be to let you seek a second opinion. Go for an operation and you will have to sign a disclaimer. Only another doctor would understand the legal clauses. Dentists are the same. As you sit in the waiting room two minutes before the appointment, the nurse presents you with a tenpage document and asks you to sign it; you do, so that if anything goes wrong, it is your fault and you still have to pay.

\section{Where's the money?}

The whole procedure should be changed to put the patient first. In every other business, the customer comes first. Ask any doctor about their pay and they will tell you they do not do it for the money, they do it for the satisfaction of helping people. Does that mean they would work for less pay? No way! It means they know what to say to maintain their status. The world's first welfare state was created by Aneurin Bevan [3] in Britain after the tragedy of the second world war. He wanted all hospitals to be government owned and all doctors to work for the government. The doctors' unions protested. They were self-employed and could charge whatever the patients would stand. Eventually Bevan had to compromise and allowed the doctors to work for others as well as the government. In other trades, this is known as moonlighting and is generally frowned upon but for doctors it is regarded as the step up to the high earnings. Private medicine was allowed to run alongside the National Health Service and gave the surgeons and those at the top of the NHS an opportunity to put in a few extra hours in private hospitals so that they can bring their total earnings to about five times more than they would get from the NHS alone. Usually insurance companies were covering the costs of treatment in the private hospitals. The doctors were the same whether the patient was in private care or the NHS. The difference being that the floors in the private hospitals are carpeted and patients had individual rooms with a television. The patient would also jump the queue. The NHS would keep the patient waiting and that wait would be longer if the surgeon was not available due to commitments in the private hospital. Bevan's socialist ambitions were thwarted, not by the patients who are the electorate, but by the doctors. Nevertheless, the NHS, now in its 70th year grumbles along with almost daily complaints about insufficient money. The assumption that spending more on health care will improve health is false and based on pleas from the medical profession. Never having worked in any other job, they think they work harder than anyone else and have higher responsibilities. How often does a doctor say, Unfortunately, you are not responding to the medication? It is the patient's fault.

\section{Payment by results}

Pay doctors and their support staff according to results and their attitude will change. All other workers are paid on this basis. Productivity is the measure of efficiency and performance. No longer should the medical profession be allowed to hide behind their failure to apply better means of healing. If a doctor is unable to cure a disease, let him sue his medical school or employers for keeping him ignorant.

\section{Patients should complain}

There are many examples where failure to cure or heal should not be tolerated. The belief that it is better to let a patient die than treat them with something that has not been proven over many years on thousands of patients is a scam perpetrated for profit by corrupt regulators supported by existing suppliers. Despite asking for innovation, the obstacles to innovation in medicine are colossal. The complaints should be aimed by patients at their politicians who control the laws and regulators governing medical practice.

\section{Non-healing wounds}

In Britain there are 140 amputations a week, mostly because diabetic ulcers cannot be healed. This figure is rising, having doubled in the last few years. An amputation costs $£ 25,000$ plus the cost of equipping the patient with a prosthesis and their rehabilitation. Twenty years ago, the ability of low powered lithotripters to heal non-healing wounds was announced by orthopaedic surgeons who had observed the effect when treating wounds; they healed better than expected. Roll forward to the present day and NICE, National Institute of Clinical Excellence, in Britain states that the technology is still experimental [4]. That statement was made by a lawyer, not a doctor. In Germany, treatments are paid for (reimbursed) by insurance companies, so they only pay for approved treatments. CellSonic VIPP was being used successfully by Dr Christian Busch [5] at Tübingen University and following a complaint by a patient to her insurer for not getting adequate treatment and knowing that Busch with his CellSonic machine could help she informed the insurer and a director then telephoned Dr Busch. He agreed that CellSonic is the best of all methods for wound healing and criticised the insurance company for reimbursing the negative pressure machine which does not work. The company director agreed and asked for $€ 400,000$ for further trials. With adequate trials already done, why should the insurance company want more money?

In 2017, the total cost of wound care in Britain was $£ 5.3$ billion. The number of wounds in a year is 2.2 million so the cost to the NHS of each wound is $£ 2,409$. As these wounds never heal, the costs run on until the patient dies or has an amputation. Even an amputation often fails to intercept the infection preventing the wound closing, so the crisis continues [6]. The cost of healing a wound with CellSonic VIPP including labour and the machine is $£ 130.00$ plus $30 \%$ for cleaning and dressings totalling £169.00. This gives a saving of $£ 2,240$ per wound $(£ 2,409$ - $£ 169$ ) which spread over 2.2 million patients would be a saving of almost $€ 5$ billion a year. This amount is of no interest to the politicians or the NHS management. They think that the answer is to have more to spend on methods that do not work. The refusal of doctors to try machines offered to them free of charge confirms a major failure in the system. They have no incentive to improve. 


\section{Pain}

One of the main reasons for absenteeism from work is lower back pain. The nurse at the local clinic will prescribe a pain killer. This will numb the brain making the pain tolerable, not cure the cause of the pain and not make the person able to perform better at work. Over many years, CellSonic VIPP has been found to cure all types of back pain and even succeeded in growing new nerves in cases of severed spinal cord. The treatment does not use drugs so there are no side effects [7]. For lower back pain, the treatment takes a few minutes and can be done by a nurse. Severed spinal cord takes longer and repeat treatments have to be carried out for a few months but given the fact that this is bringing a patient back from paralysis it is a breakthrough that restores life to a patient. I met a young girl in India who had been treated and asked her if she could now tell when she needed to go to the toilet. She smiled and realised I appreciated the enormity of her predicament. Her nerves from the waist downwards were working again. She was now getting back her dignity and independence. Only Cellsonic VIPP is able to bring about this transformation [8].

\section{Cancer}

A third of the world's population is affected by cancer at some stage in their life and it remains a major killer. There is a general belief that cancer is caused by a bio-chemical failure and the cure has to be a drug. The aim is to selectively kill cancer cells with a deadly poison called chemotherapy (banned in warfare where is it known as mustard gas) but it also kills all cells, not just mutating cells. Radiation is more dangerous and causes cancer, yet it is used to burn away cancer cells whilst trying to avoid harming adjacent healthy cells. The cure rates from chemo and radiation are miserably low and during the treatment the patient is tortured.

\section{CellSonic VIPP has been described by Dr Steve Halti wanger [9]}

When you educated me on the fact that CellSonic not only produced sound waves but also CellSonic produces a short duration, high powered electrical field it looks more likely that you have created a nonsurgical form of irreversible electroporation using a combination of sound waves PLUS a high-powered electric field. The combination of VIPP sound and high-powered electrical fields have never been combined before to my knowledge to treat cancer. Noble prize work if you can live to collect it. This is a paradigmbreaking disruptive technology. WOW!

\section{I think we now have a good working theory to explain why VIPP works in cancer}

In my opinion, it is the combined effect of sound and electric field that produces the unique effects of VIPP which is why your technology is different from your competitors. So, if I can hang around, I may get a Nobel prize for medicine. Great! The real reward will be to know that deaths and pain have been halted. It surprises me that the medical establishment does not want a cancer cure. In Britain, the 1939 Cancer Act forbids advertising anything to do with cancer. The purpose is to prevent people being given false hope. Why that act was used to threaten a company selling a bright light to help a woman check if there are lumps in her breast only the woman at the Advertising Standards Agency knows. The breast light had been approved by a renowned doctor [10]. Their website now refers to cancer, so I hope they are not now legally threatened.

\section{The opioid crisis}

In the USA, the opioid crisis is killing and costing. The Financial Times article [11] says that pharmaceutical companies will be sued just as tobacco companies were sued for the damage their products inflicted on the innocent public [12]. The US Department of Health and Human Services reports [13] that in the late 1990s, pharmaceutical companies reassured the medical community that patients would not become addicted to opioid pain relievers and healthcare providers began to prescribe them at greater rates. Increased prescription of opioid medications led to widespread misuse of both prescription and non-prescription opioids before it became clear that these medications could indeed be highly addictive.

At the core of this problem is pain and mostly the pain of cancer. CellSonic VIPP has now been approved in the USA to treat pain in Stages III \& IV Cancer and chronic disease Patients. The CIRBI link is Pro0002913 and the submission was written by Annie Brandt of the Best Answer for Cancer Foundation [14]. CellSonic does not use drugs so there are no side effects and the results are apparent within three days. The procedure works on all types of cancers. Big Pharma is in a self-inflicted crisis. CellSonic can help them as well as patients. Cancer is an electrical fault as explained by the researchers at Bradford University in England [15]. Pharmaceuticals will not resolve an electrical fault.

\section{The value of life}

With the title of this article suggesting that doctors should be paid more, the question should now be that if CellSonic can save the life of a cancer patient, what could the doctor charge? To help answer this, we have the value of a life. In August 2018, a jury in California awarded $\$ 289$ million to a school's ground-keeper with cancer after finding that the weed killer he used had not adequately described the risks to human health. The weed killer contained glyphosate and was made by Monsanto, a chemicals company that was recently taken over by Bayer. The German company's share price plunged after the jury's decision [16].

Does this mean that CellSonic should approach the victim and offer to clear his cancer for $\$ 289$ million less a sum to pay for the legal costs he has suffered? The idea is fanciful, but the amount of money is real. This is what a court places on the value of the man's shortened life and discomfort. There are millions of people 
suffering as is this man and their cancers are the results of all things such as tobacco, pollution, electrical powerlines, smartphones and the stress of divorce. The cost of treating cancer with CellSonic is about the same as healing a wound. It is not even as much as one night's board in a private hospital. Therefore, the profit margin could be astronomical. It won't be because I will not allow it and it will cost considerably less than the useless cancer treatments now inflicted. In the USA, a cancer patient incurs a spend of $\$ 200,000$ a year either personally or from an insurance company and they die in the fifth year.

\section{Conclusion}

With doctors paid by results, they would increase their incomes by providing a better service. Only by changing the terms of remuneration will doctors be lifted out of their complacency and be taken back to the basics; by the best means available, to save their patients from pain and death. Like any other tradesman, they need the right tools to do the job and that equipment is readily available and affordable.

\section{References}

1 https://www.trinityholistic.com/bio/ Dr Mike Andreano

2 https://www.statnews.com/2018/08/14/medical-students-skippingclass/
3 https://en.wikipedia.org/wiki/Aneurin_Bevan

4 http://www.bbc.co.uk/history/historic_figures/bevan_aneurin.shtml

5 Email from NICE sent 01 May 2018 10:29 to Cell Sonic

6 http://www.cellsonic-medical.com/wound.htm with published papers

7 https://www.nursingtimes.net/Journals/2015/06/05/q/f/y/Theburden-of-chronic-wounds-in-the-UK.pdf

8 http://www.cellsonic-medical.com/pain.htm

9 http://www.oatext.com/spinal-cord-injury-patient-treated-with-cellbased-therapy-and-cellsonic-vipp.php

$10 \mathrm{http} / / /$ www.royalrife.com/haltiwanger1.pdf

11 https://www.breastlight.com/

12 https: //www.ft.com/content/cb112920-8079-11e8-bc5550daf11b720d

13 https://www.drugabuse.gov/drugs-abuse/opioids/opioid-overdosecrisis

14 https://www.hhs.gov/opioids/about-the-epidemic/index.html

15 https://bestanswerforcancer.org/

16 http://143.53.36.235:8080/sjsacad.htm

17 https://www.economist.com/the-world-this-week/2018/08/18/ business-this-week?cid1=cust/ednew/n/bl/n/2018/08/16n/owned/ $\mathrm{n} / \mathrm{n} / \mathrm{nwl} / \mathrm{n} / \mathrm{n} / \mathrm{me} / 144433 / \mathrm{n}$

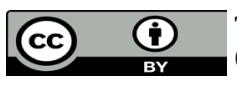

This work is licensed under Creative Commons Attribution 4.0 License

To Submit Your Article Click Here:

Submit Article

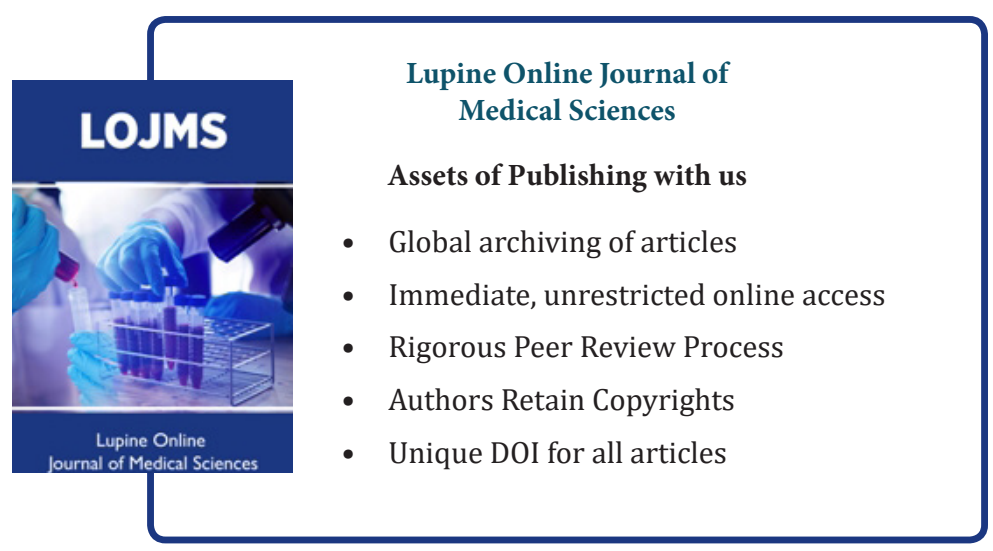

